\title{
Wagner-Vengrenovich Distribution
}

\author{
Bohdan V. Ivanskii, Anatolii V. Moskalyuk, Sergey V. Yarema, \\ Igor I. Panko, and Miroslav O. Stasyk
}

Yuriy Fedkovych Chernivtsi National University, 2, Kotsyubynsky St., Chernivtsi 58012, Ukraine

Correspondence should be addressed to Anatolii V. Moskalyuk; moskalyuk@i.ua

Received 24 April 2013; Accepted 22 May 2013

Academic Editors: M. R. Ferreira, A. Fidalgo, and A. Ohtaka

Copyright (C) 2013 Bohdan V. Ivanskii et al. This is an open access article distributed under the Creative Commons Attribution License, which permits unrestricted use, distribution, and reproduction in any medium, provided the original work is properly cited.

\begin{abstract}
The process of coarsening of nanoclusters or nanocrystals (NCs) is investigated for the case when cluster growth (dissolution) is governed simultaneously by both diffusion along dislocation pipes and the rate of formation of chemical connections (chemical reaction) at cluster surface, namely, Wagner's growing mechanism. For that, the total flow of atoms to (from) a cluster is represented by two parts, namely, diffusion part and the Wagner (kinetic) one. The dependence of the rate of growth of NC on the ratio of the parts of the total flow has been determined as well as the NC's size distribution function referred to as the Wagner-Vengrenovich distribution. Computed distribution is compared with experimentally obtained histograms.
\end{abstract}

\section{Introduction}

Ostwald's ripening (OR) is the final stage of formation of a new phase as a result of phase transformation, such as decay of oversaturated solid solutions. Nanoclusters or nanocrystals (NCs) of new phase having different sizes interact through the Gibbs-Thomson effect that results in dissolution of small $\mathrm{NC}$ and growth of large ones. Diffusion growth of NC under matrix of volume diffusion ( $l s$-mechanism) has been firstly studied by Lifshitz and Slyozov [1,2]. Wagner has showed later [3] that beside diffusion mechanism, another mechanism of NC growth is possible, which is governed by the rate of formation of chemical connections (chemical reaction) at NC surface ( $w$-mechanism). The theory developed in the cited papers is referred to as the LSW theory. Practical verification of this theory shows that in many cases, it is proper for the description of experimental data on temporal behavior of the mean NC size and the NC size the distribution function, while in other cases the LSW theory must be refined.

In this connection, $\mathrm{NC}$ growth is considered in papers [4, $5]$ as a result of combined action of two growing mechanisms, diffusion $(l s)$ and Wagner's $(w)$ ones. In the framework of the modified LSW theory and taking into account both mechanisms of growing ( $l s$ and $w$ ), we can obtain a size distribution in the form of the generalized Lifschitz-SlyozovWagner distribution [4]. This distribution can refer to a much wider range of the experimental histograms than each of the Lifschitz-Slyozov (LS) and Wagner's $(W)$ distributions separately.

The products of nanotechnologies [6-8] become new objects of applying the LSW theory. As sizes become $100 \mathrm{~nm}$ and less [9], the characteristics of both separate NCs and of the system as a whole change cardinally that provides practically useful properties. The OR is among probable factors destabilizing microstructure and properties of nanocluster systems. Semiconductor heterosystems with quantum dots (QDs) obtained by electron-beam epitaxy technique [10-16] in the Stranski-Krastanov regime [17] as well as arrays of QDs synthesized from liquid matter by chemical and other techniques [18-25] are examples of such nanocluster systems.

As it has been mentioned above, the generalized LSW distribution has been obtained by combination of the diffusion $(l s)$ and Wagner's $(w)$ mechanisms of NC growth. However, in presence of a matrix of free dislocations interacting with elastic fields of NCs or in presence of NCs located at dislocation network, just dislocation diffusion ( $v$-mechanism of NC growth) predominates rather than matrix one. Peculiarities of the Ostwald's ripening under diffusion along dislocation pipes have been considered supra [26-30]. 
The purpose of this paper consists in finding out the size distribution function and temporal dependences of NC mean size for the case when NC growth is governed simultaneously by both mechanisms, namely, dislocation diffusion $(v)$ and the rate of formation of chemical connections (chemical reaction) at cluster surface $(w)$. Computations are carried out within the framework of the modified LSW theory [4], using the technique introduced in paper [31].

\section{Theoretical Part}

As NC growth is governed by two mechanisms ( $v$ and $w$ ) simultaneously, the total flow of atoms to (from) NC consists of two parts [4]

$$
j=j_{d}+j_{i}
$$

where $j_{d}$ is the diffusion part of flow that equals the number of atoms reaching cluster surface in unit time through dislocation diffusion and $j_{i}$ is the Wagner's part of flow that equals the number of atoms involved in forming chemical connections at cluster surface in unit time.

To determine the size distribution function, $f(r, t)$, let us use the continuity equation

$$
\frac{\partial f(r, t)}{\partial t}+\frac{\partial}{\partial r}[f(r, t) \cdot \dot{r}]=0,
$$

where $\dot{r} \equiv d r / d t$ is the rate of growth of cluster with radius $r$, which is determined from the following condition:

$$
\frac{d}{d t}\left(\frac{4}{3} \pi r^{3}\right)=j v_{m}
$$

where $j$ is determined by (1).

In accordance with [27], the diffusion part of a flow equals

$$
j_{d}=D_{d} 2 Z q \frac{\langle C\rangle-C_{r}}{r}
$$

where $D_{d}$ is the diffusion coefficient along dislocations, $Z$ is the the number of dislocation lines crossing a cluster ( $Z$ = const), $q$ is the cross-section of dislocation pipe, $\langle C\rangle$ is the mean concentration of diffusing atoms into solution, $C_{r}=C_{\infty} \exp \left(2 \sigma v_{m} / r k T\right) \approx C_{\infty}\left(1+2 \sigma v_{m} / r k T\right)$ is that concentration of atoms of solved matter at the boundary of a cluster of radius $r, C_{\infty}$ is that equilibrium concentration for the specified temperature $T$, and $v_{m}$ is that volume of an atom of solved matter.

Wagner's (kinetic) part of a flow equals [3]:

$$
j_{i}=4 \pi r^{2} \beta\left(\langle C\rangle-C_{r}\right),
$$

where $\beta$ is the kinetic coefficient.

Knowing $j_{d}$ and $j_{i}$, one finds out the rate of cluster growth from (3). Consider the following:

$$
\frac{d r}{d t}=\frac{1}{4 \pi r^{2}}\left[D_{d} 2 Z q \frac{\left(\langle C\rangle-C_{r}\right)}{r}+4 \pi r^{2} \beta\left(\langle C\rangle-C_{r}\right)\right],
$$

where $\langle C\rangle-C_{r}=\left(2 \sigma v_{m} / k T\right)\left(1 / r_{k}-1 / r\right), r_{k}$ is the critical radius that, within the LSW theory approximation, assumes to be equal to the mean radius, $\langle r\rangle$.
To determine the analytical form of the size distribution function of clusters with peculiarities intrinsic in Wagner's $(W)$ distribution [3] and Vengrenovich's $(V)$ distribution [27], one must express the rate of growth (6) as the ratio of flows $j_{d}$ and $j_{i}$

$$
\frac{j_{d}}{j_{i}}=\frac{x}{1-x}
$$

where $x$ is the part of flow $j_{d}$ in the total flow $j: x=j_{d} / j$ and $(1-x)$ is the part of flow $j_{i}$ in the total flow $j: 1-x=j_{i} / j$. Taking into account that (4) and (5) for flows are valid for NCs of arbitrary radius $r$, including NCs of the maximal size $r_{g}[4,5]$, one can rewrite $(6)$ in the form

$$
\frac{d r}{d t}=\frac{A^{*}}{r}\left(\frac{x}{1-x} \frac{1}{u^{3}}+1\right)\left(\frac{r}{r_{k}}-1\right),
$$

where $A^{*}=2 \sigma v_{m}^{2} C_{\infty} \beta / k T, u=r / r_{g}$, or in the form

$$
\frac{d r}{d t}=\frac{B^{*}}{r^{4}}\left(1+\frac{1-x}{x} u^{3}\right)\left(\frac{r}{r_{k}}-1\right),
$$

where $B^{*}=\left(2 \sigma v_{m}^{2} C_{\infty} Z q D_{d}\right) / \pi k T$.

Equation (8) corresponds to the rate of growth of NCs that is determined by the kinetic flow $j_{i}$, namely, by the rate of formation of chemical connections, with the share contribution $(1-x)$ of the diffuse flow $(x<1)$, and the rate of growth (9) is determined by the diffuse flow $j_{d}$ with the share contribution $x$ of the kinetic flow $(x>0)$.

From (8) or (9), for the rate of growth, one can determine the ratio $r_{g} / r_{k}$ that in terms of paper [1] corresponds to the locking point magnitude, $u_{0}\left(u_{0}=r_{g} / r_{k}\right)$. Knowing $u_{0}$ enables to integrate (8) and (9) and to find out temporal dependences for $r_{g}$ and $r_{k}$, as well as to separate the variables in the continuity equation (2) and to find out the analytical form of the size distribution function. In accordance with [31], the ratio $\left(r_{g} / r_{k}\right)\left(u_{0}\right)$ can be found out from the dependence of the specific rate of growth $\dot{r} / r$ on $r$ shown schematically in Figure 1. Derivative equals zero at the maximum of this function

$$
\left.\frac{d}{d r}\left(\frac{\dot{r}}{r}\right)\right|_{r}=0
$$

From (10), one obtains

$$
\frac{r_{g}}{r_{k}}=\frac{2+3 x}{1+3 x}
$$

Assuming $r=r_{g}(u=1)$ in (8) and replacing the ratio $r_{g} / r_{k}$ by its magnitude from (11), one obtains by integration

$$
r_{g}^{2}=\frac{2 A^{*}}{(1-x)(1+3 x)} t, \quad r_{k}^{2}=\frac{2 A^{*}(1+3 x)}{(1-x)(2+3 x)^{2}} t .
$$

Equation (12) determines the temporal dependences for the maximal radius of NCs, $r_{g}$, and the critical one, $r_{k}$, when the Wagner's mechanism of growth predominates. The limits of changing parameter $x$ can be determined from comparison 


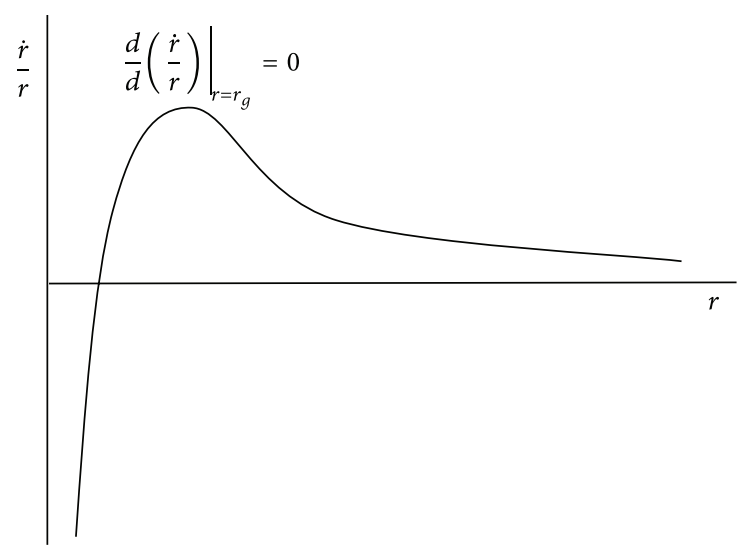

FIGURE 1: Schematic representation of the specific rate of growth $(\dot{r} / r)$ on $r$.

of experimental and theoretical data, for example, for size distribution function, which equals in our case $0 \leq x \leq 0,3$, approximately.

For $x=0$, growth of NCs is completely controlled by the rate of formation of chemical connections (the $w$ mechanism) [3]

$$
r_{g}^{2}=2 A^{*} t, \quad r_{k}^{2}=\frac{1}{2} A^{*} t, \quad \frac{r_{g}}{r_{k}}=2 .
$$

Similarly, one obtains from (9)

$$
r_{g}^{5}=\frac{5 B^{*}}{x(1+3 x)} t, \quad r_{k}^{5}=\frac{5 B^{*}(1+3 x)^{4}}{x(2+3 x)^{5}} t .
$$

Equation (14) corresponds to the temporal dependences of changing $r_{g}$ and $r_{k}$, when diffusion along dislocation pipes predominates in the growth of NCs. For that, the parameter $x$ changes within interval $0,7 \leq x \leq 1$, approximately.

For $x=1$, growth of NCs is completely controlled by the diffusion of solved atoms along dislocation pipes (the $v$ mechanism) $[26,27]$ :

$$
r_{g}^{5}=\frac{5}{4} B^{*} t, \quad r_{k}^{5}=\left(\frac{4}{5}\right)^{4} B^{*} t, \quad \frac{r_{g}}{r_{k}}=\frac{5}{4} .
$$

In accordance with [26], the total change of NC's volume, $\Delta V_{\Sigma}$, consists from $\Delta V_{d}$, that is, the change caused by the dislocation flux, $j_{d}$, and $\Delta V_{i}$ caused by the kinetic flux, $j_{i}$,

$$
\Delta V_{\Sigma}=\Delta V_{d}+\Delta V_{i}
$$

or

$$
\frac{4}{3} \pi r_{k_{\Sigma}}^{3}=\frac{4}{3} \pi r_{k_{d}}^{3}+\frac{4}{3} \pi r_{k_{i}}^{3},
$$

where for the sake of simplicity, time reading is made from zero: $t=t_{0}=0 ; r_{k_{\Sigma}}^{3}\left(t_{0}\right)=0 ; r_{k_{d}}^{3}\left(t_{0}\right)=0 ; r_{k_{i}}^{3}\left(t_{0}\right)=0$. Taking into account (12) and (14), one obtains from (17)

$$
r_{k_{\Sigma}}=\left[f_{1}(x) t^{3 / 5}+f_{2}(x) t^{3 / 2}\right]^{1 / 3},
$$

where $f_{1}(x)=5 B^{*}(1+3 x)^{4} / x(2+3 x)^{5}, f_{2}(x)=2 A^{*}(1+$ $3 x) /(1-x)(2+3 x)^{2}$, and the limits of changing total radius of NCs $x$ are $0,3 \leq x \leq 0,7$, approximately.

In accordance with [31], the size distribution function of NCs is found out as the product of two functions

$$
f(r, t)=\varphi\left(r_{g}\right) g^{\prime}(u),
$$

where $r_{g}=\psi(t)$.

By substitution (19) into the mass conservation law for disperse phase (NCs),

$$
M=\frac{4}{3} \pi \rho \int_{0}^{r_{g}} r^{3} f(r, t) d r,
$$

one obtains

$$
\varphi\left(r_{g}\right)=\frac{Q}{r_{g}^{4}},
$$

where $Q=3 M / 4 \pi \rho \int_{0}^{1} u^{3} g^{\prime}(u) d u$.

Taking into account (21), one can write the size distribution function in the form

$$
f(r, t)=\frac{1}{r_{g}^{4}} g(u),
$$

where

$$
g(u)=Q g^{\prime}(u),
$$

and $g(u)$ is the required distribution function on relative sizes of NCs, called by us the Wagner-Vengrenovich (WV) distribution function, as the distributions corresponding to each of the mechanisms, $w$ and $v$, separately have been early obtained by Wagner $(W)[3]$ and Vengrenovich $(V)$ [27].

For determining $g^{\prime}(u)$, let us use the continuity equation (2) substituting in this equation, instead of $f(r, t)$ and $\dot{r}$, their magnitudes from (19) and (8) (or (9)). By transition in (2), from differentiation on $r$ and $t$ to differentiation on $u$ [31], variables are separated

$$
\frac{d g^{\prime}(u)}{g^{\prime}(u)}=-\frac{4 v_{g} u^{2}+v-u(d v / d u)}{u^{3} v_{g}-v u} d u
$$

where one takes into account that $v=\dot{r} r / A^{*}, v_{g}=\dot{r}_{g} r / A^{*}$, $d u / d r=1 / r_{g}$, and $d u / d r_{g}=-u / r_{g}$.

Finding out $v, v_{g}$, and $d v / d u$ from (8), one can rewrite (24) in the form

$$
\begin{aligned}
& \frac{d g^{\prime}(u)}{g^{\prime}(u)} \\
& =-\frac{4 u^{5}+u^{3}\left(3 x^{2}-2 x-1\right)+u x(9 x+6)-12 x^{2}-4 x}{u(1-u)^{2}\left[u^{3}+u^{2} x(3 x-1)+3 u x^{2}+x(3 x+1)\right]} \\
& \quad \times d u,
\end{aligned}
$$




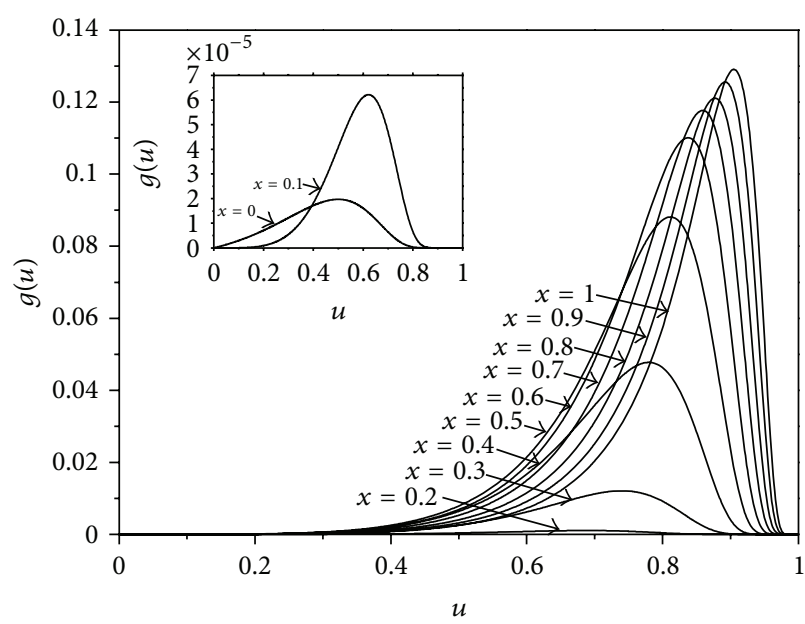

(a)

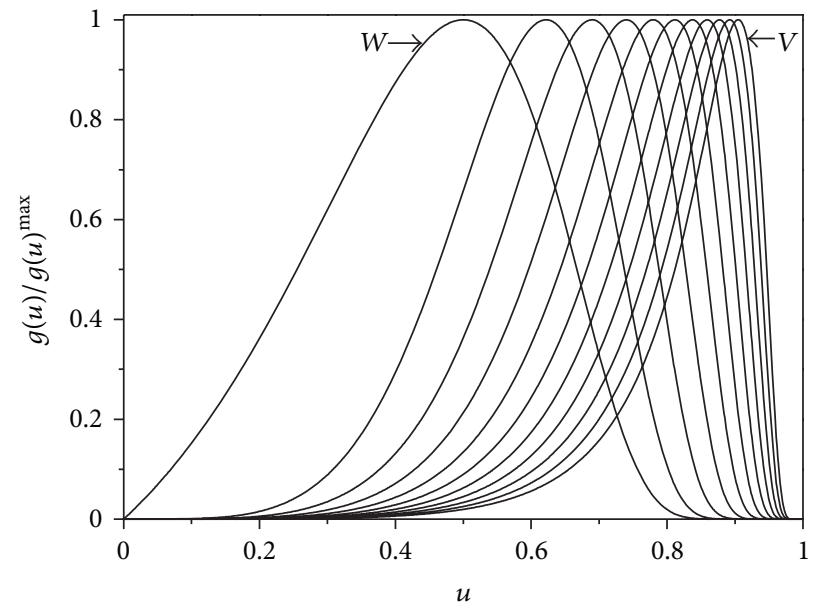

(b)

FIGURE 2: Dependences corresponding to the WV distribution computed with interval $\Delta x=0,1$ (a); the same dependences normalized by the corresponding maxima (b).

by integration of which one obtains the WV size distribution function:

$$
\begin{aligned}
g^{\prime}(u)= & u^{\sigma}(1-u)^{-\alpha}(u+b)^{\beta}\left(u^{2}+c u+d\right)^{\gamma} \exp \left(\frac{\omega}{1-u}\right) \\
& \times \exp \left[\frac{\varepsilon-\gamma c}{\sqrt{d-c^{2} / 4}} \tan ^{-1}\left(\frac{u+(c / 2)}{\sqrt{d-\left(c^{2} / 4\right)}}\right)\right],
\end{aligned}
$$

with the magnitudes of the power indices, $\sigma, \alpha, \beta, \gamma$, and coefficients $\gamma, \varepsilon, c$, and $d$ expressed through the parameter $x$ are given in the appendix.

\section{Results and Discussion}

The WV distribution is represented in Figure 2. Dependences represented in Figure 2(a) are computed with interval $\Delta x=$ 0,1 . The same dependences normalized by their maxima are represented in Figure 2(b). In the normalized form, such dependences are well behaved for comparison with the normalized experimentally obtained histograms.

The results of comparison of the experimentally obtained histograms with our computations, (23), are shown in Figure 3 for various magnitudes of the parameter $x$. All experimentally obtained histograms and theoretically found dependences are normalized by their maxima. For convenience, the LS distribution is represented, accurate within a constant, as a function of variable $u=r / r_{g}$ :

$$
g^{\prime}(u)=u^{2}(1-u)^{-11 / 3}(u+2)^{-7 / 3} \exp \left(-\frac{1}{1-u}\right) .
$$

Experimentally obtained histograms shown in Figure 3 correspond to the size distribution function of $\mathrm{Al}_{3} \mathrm{Sc} \mathrm{NCs}$ in binary alloys $\mathrm{Al}-\mathrm{Sc}(0,12 \mathrm{am} \% \mathrm{Sc})$. Exposition of alloys has been performed at temperature $350^{\circ} \mathrm{C}$ over a period: (a) 2; (b) 5; (c) 72; (d) 104; (e) $168 \mathrm{~h}$ [32]. Dashed curves correspond to the LS, $W(x=0)$, and $V(x=1)$ distributions. Solid curve corresponds to the WV distribution for relevant magnitudes of the parameter $x$. One can see that neither the $W$ distribution $(x=0)$ nor the $V$ distribution $(x=$ 1 ) is well fitting the experimentally obtained histograms. The LS distribution (dashed curve) and the WV distribution for relevant magnitude of the parameter $x$ (solid curve) fit experimentally obtained histograms much more reliably. Moreover, one can see from Figure 3 that the WV distribution (23) provides better fitting of experimental data than the LS distribution.

The same is observed for alloys $\mathrm{Al}(\mathrm{Sc}, \mathrm{Zr}$ ). Histograms in Figure 4 correspond to size distribution of $\mathrm{NCs} \mathrm{Al}_{3} \mathrm{Sc}_{1-x} \mathrm{Zr}_{x}$ in such alloys [33]. Alloys (Al-0,14Sc-0,012Zr)am\% were exposed at temperature $375^{\circ} \mathrm{C}$ over a period: (a) 3; (b) 192; (c) $288 \mathrm{~h}$. Similarly to the case of binary alloys, the WV distribution (23) satisfactorily fits experimentally obtained histograms. It means that the proposed mechanism of cluster coarsening governed by two mechanisms ( $w$ and $l s$ ones) in parallel is realized under the OR. For that, interpretation of experimentally obtained histograms is made by applying the WV distribution.

\section{Conclusions}

Summarizing, it has been shown that the modified LifshitzSlyozov-Wagner (LSW) theory $[4,5]$ can be applied to nanocluster systems. Theory of the Ostwald's ripening for alloys containing nanocrystalline phases must be assumed taking into account not only diffusion flow, $j_{d}$, but also kinetic (Wagner's) one, $j_{i}$, it has been shown, for alloys containing $\mathrm{Al}-\mathrm{Sc}$ and $\mathrm{Al}(\mathrm{Sc}, \mathrm{Zr})$, correspondingly, $\mathrm{NCs} \mathrm{Al}_{3} \mathrm{Sc}$ and $\mathrm{Al}_{3}\left(\mathrm{Sc}_{1-x} \mathrm{Zr}_{x}\right)$, that the size distribution function is satisfactorily fitted by the introduced Wagner-Vengrenovich (WV) distribution here. 


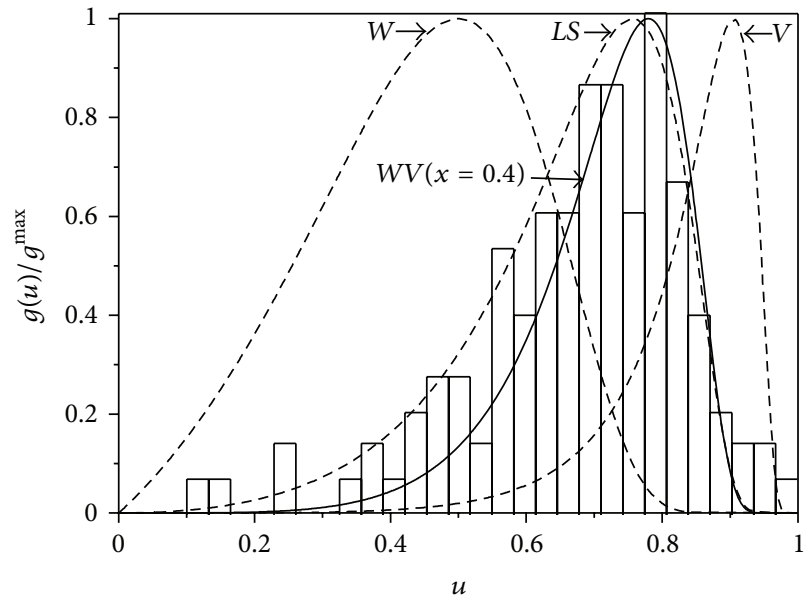

(a)

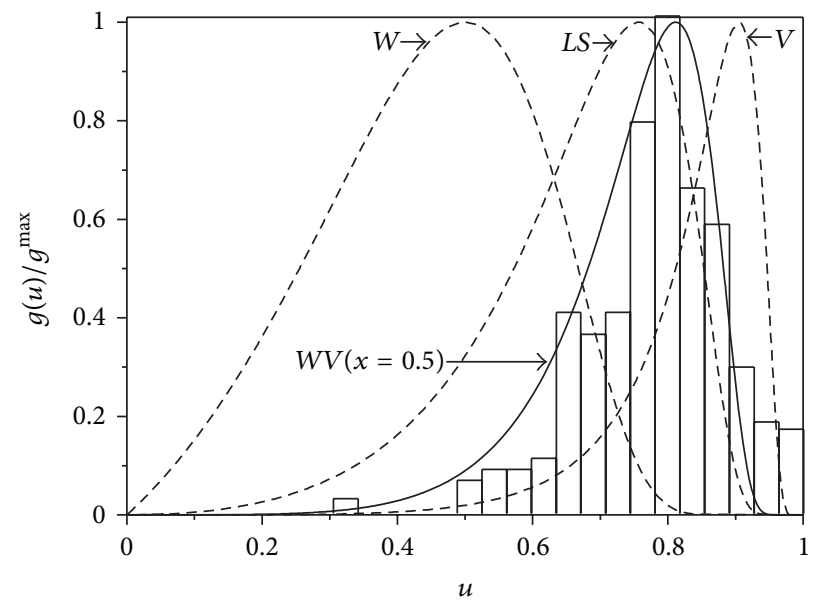

(c)

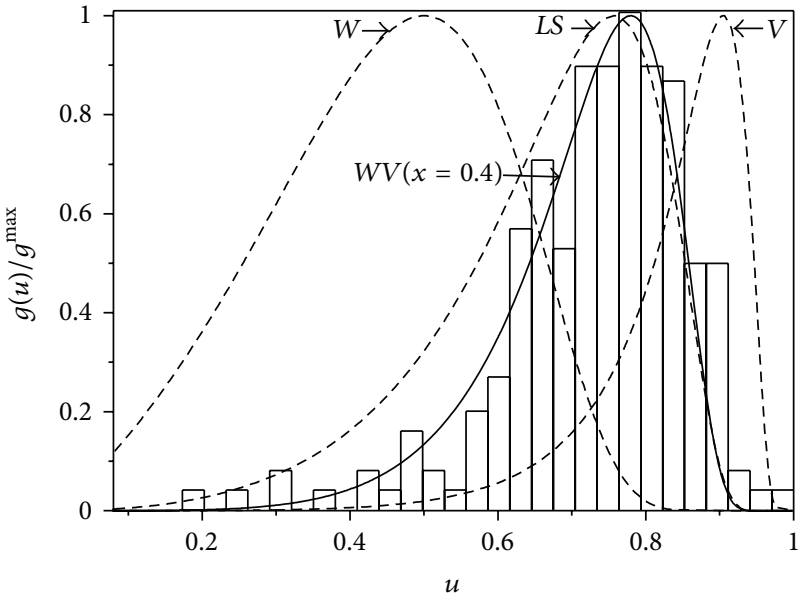

(b)

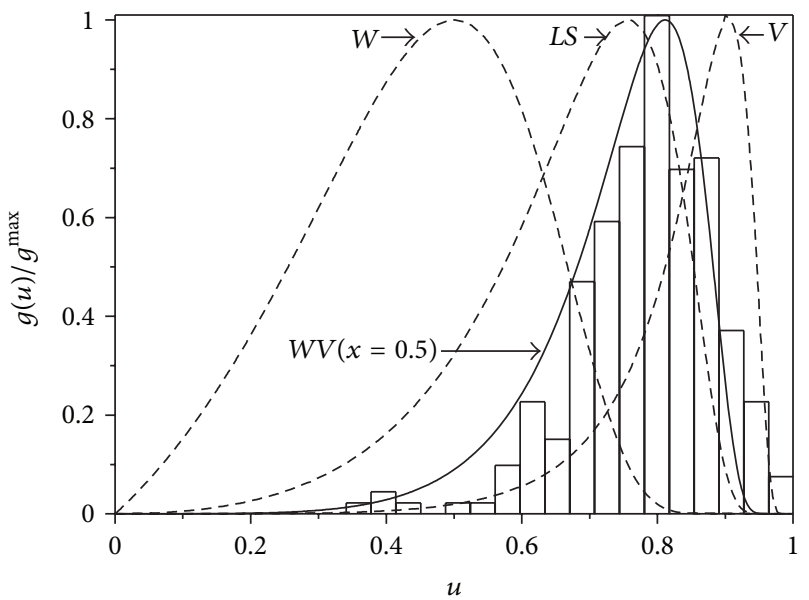

(d)

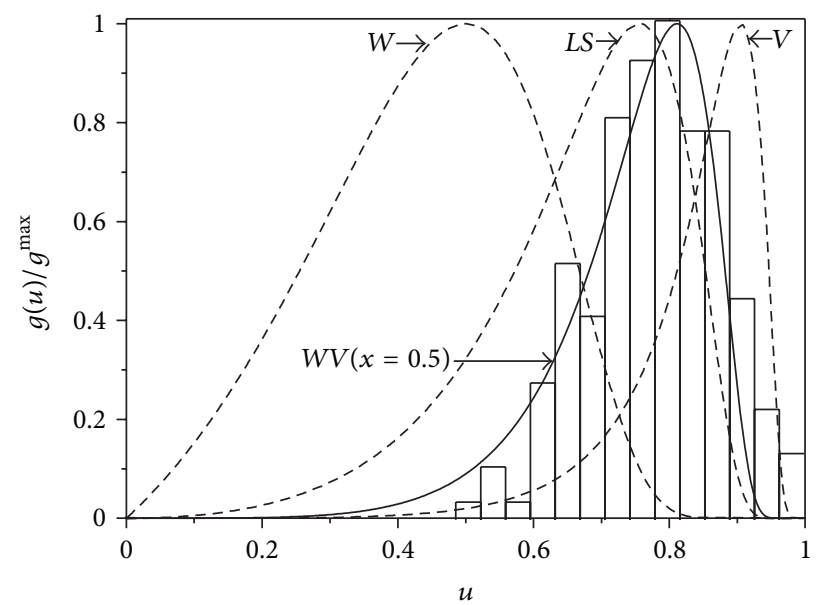

(e)

FIGURE 3: Comparison of experimentally obtained histograms of $\mathrm{Al}_{3} \mathrm{Sc}$ NCs [32] with the WV distribution (solid curve) for exposition of alloys for temperature $350^{\circ} \mathrm{C}$ over a period: (a) 2; (b) 5 ; (c) 72 ; (d) 104 ; (e) $168 \mathrm{~h}$. 


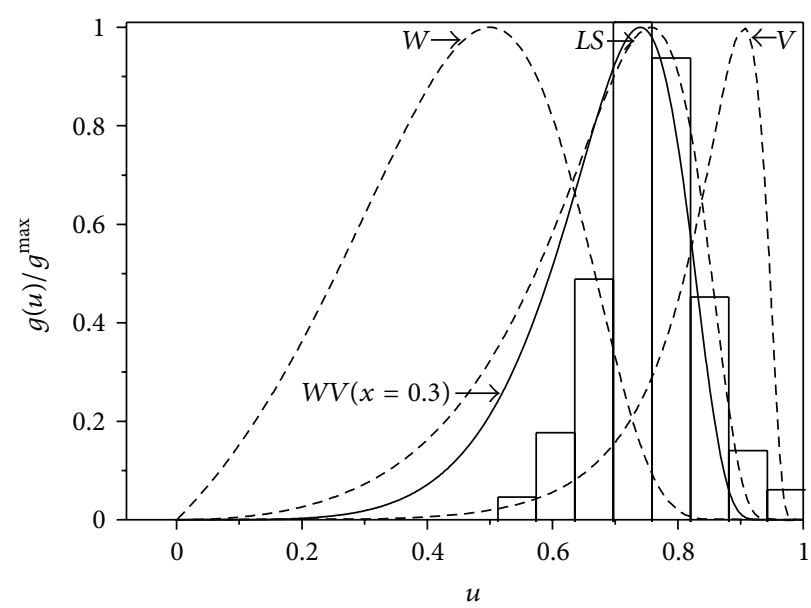

(a)

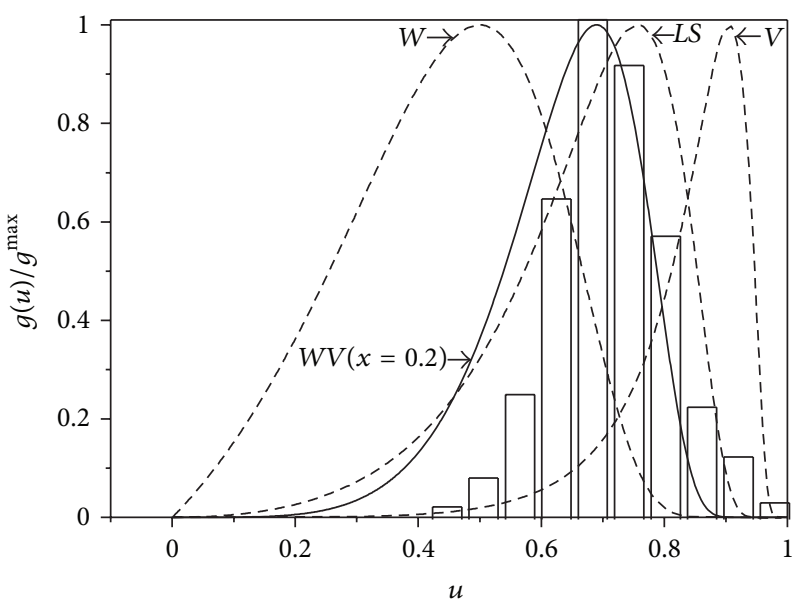

(b)

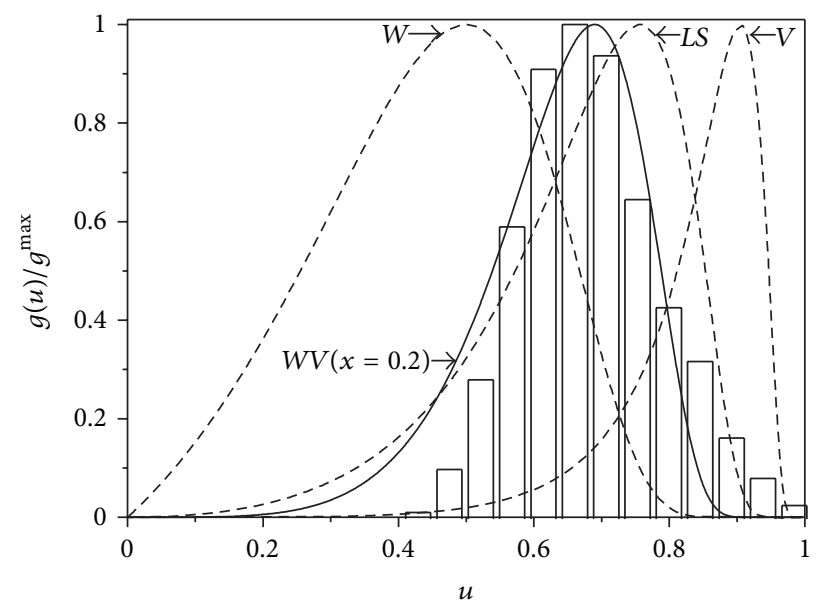

(c)

FIGURE 4: Comparison of experimentally obtained histograms of $\mathrm{Al}_{3} \mathrm{Sc}_{1-x} \mathrm{Zr}_{x} \mathrm{NCs}$ [33] with the WV distribution (solid curve) for exposition of aluminium-based alloys containing $0,14 \mathrm{Sc}$ and $0,012 \mathrm{Zr}$ at \% for temperature $375^{\circ} \mathrm{C}$ over a period: (a) 3 ; (b) 192 ; (c) $288 \mathrm{~h}$.

\section{Appendix}

To integrate (25) for determining $g^{\prime}(u)$, one must perform prime factor decomposition of the third-order polynomial into denominator in respect of $u$

$$
\begin{aligned}
u^{3} & +u^{2} x(3 x-1)+u 3 x^{2}+x(3 x+1) \\
& =(u+b)\left(u^{2}+c u+d\right),
\end{aligned}
$$

where the root of the cubic equation (A.1), found using the Cardano formula, has the form:

$$
\begin{gathered}
b=\frac{\mu}{3}-w-v, \\
\mu=3 x^{2}-x, \quad w=\sqrt{-\frac{q}{2}+\sqrt{z}}, \\
\nu=\sqrt{-\frac{q}{2}-\sqrt{z}}, \quad q=\frac{2 \mu^{3}}{27}-\frac{\mu s}{3}+t,
\end{gathered}
$$

$$
\begin{gathered}
s=3 x^{2}, \quad t=3 x^{2}+x, \quad z=\left(\frac{p}{3}\right)^{3}+\left(\frac{q}{2}\right)^{3}, \\
p=\frac{3 s-\mu^{2}}{3},
\end{gathered}
$$

and the coefficients are

$$
\begin{gathered}
c=\frac{2}{3} \mu+w+\nu \\
d=\left(\frac{w+v}{2}\right)^{2}+\left(\frac{w+v}{3}\right) \mu+\left(\frac{\mu}{3}\right)^{2}+\frac{3}{4}(w-v)^{2} .
\end{gathered}
$$

Taking into account (A.1), one obtains by integrating (25), the WV distribution (26), where 


$$
\begin{gathered}
\sigma=\frac{4 x(3 x+1)}{b d}, \\
\alpha=\left(18 x^{2}(b+1)(c+d+1)+11(b c+d)\right. \\
+8(b+c)+14 b d+5) \\
\times\left(\left(b^{2}+2 b+1\right)\right. \\
\left.\times\left(c^{2}+d^{2}+2 c d+2 c+2 d+1\right)\right)^{-1}, \\
\beta=\frac{\left(3 b^{3}+9 b+12\right) x^{2}+\left(6 b-2 b^{3}+4\right) x+4 b^{5}-b^{3}}{b\left(b^{2}-b c+d\right)\left(b^{2}+2 b+1\right)}, \\
\gamma=\frac{\alpha-\sigma-\beta-4}{2}, \quad \frac{3}{(b+1)(c+d+1)}, \\
\varepsilon=\sigma(2-b-c)+\alpha(b-1) \\
-\omega+\beta(2-c)+2 \gamma(2-b) .
\end{gathered}
$$

For vanishing $x(x \rightarrow 0)$, one has $\sigma \rightarrow 4, \alpha \rightarrow 5, \omega \rightarrow$ $-3, \beta \rightarrow-1, \gamma \rightarrow-1$, and $\varepsilon \rightarrow 0$, and the distribution (26), accurate within a constant $Q$, corresponds to Wagner's distribution [3]:

$$
g^{\prime}(u)=u(1-u)^{-5} \exp \left(-\frac{3}{1-u}\right) .
$$

For example, for $x=10^{-10}$, one obtains $\sigma=3,999999$, $\alpha=5,000000, \omega=-3,000000, \beta=-0,999999, \gamma=$ $-0,999999, \varepsilon=0,000464, b=0,000473, c=-0,000462$, and $d=0,0000002$. All computations have been carried out using Maple software. It must be noticed that, in accordance with (8) and (9), $x$ cannot be equal to 0 or $1: 0<x<1$.

In another case, when $x$ approaches unity, $x \rightarrow 1$, to say for $x=0,99999$, one obtains $\sigma \approx 4 ; \alpha \approx 2,88889 ; \beta \approx$ $-1,69341 ; \gamma \approx-1,70329 ; \omega \approx-0,29999 ; \varepsilon \approx-0,78535 ; b \approx$ 1,$65063 ; c \approx 0,34937 ; d \approx 2,42332$. The distribution (26), accurate within a constant $Q$, corresponds to Vengrenovich's $(V)$ distribution [27]:

$$
\begin{aligned}
g^{\prime}(u)= & \left(u^{4} \exp \left(-\frac{0,3}{1-u}\right)\right. \\
& \left.\quad \times \exp \left[-0,123 \cdot \tan ^{-1}(0,64647 u+0,11293)\right]\right) \\
\times & \left((1-u)^{2,88889}(u+1,65063)^{1,69341}\right. \\
& \left.\times\left(u^{2}+0,34937 u+2,42332\right)^{1,70329}\right)^{-1} .
\end{aligned}
$$

\section{References}

[1] I. M. Lifshits and V. V. Slyozov, "On kinetics of diffusion decay of oversaturated solid solutions," JETP, vol. 35, pp. 479-492, 1958.

[2] I. M. Lifshitz and V. V. Slyozov, "The kinetics of precipitation from supersaturated solid solutions," Journal of Physics and Chemistry of Solids, vol. 19, no. 1-2, pp. 35-50, 1961.
[3] C. Wagner, "Theorie der Alterung von Niderschlagen durch Umlösen (Ostwald Reifung)," Zeitschrift Für Elektrochemie, vol. 65, no. 7-8, pp. 581-591, 1961.

[4] R. D. Vengrenovich, B. V. Ivanskii, and A. V. Moskalyuk, "Generalized Lifshitz-Slyozov-Wagnerdistribution," JETP, vol. 131, pp. 1040-1047, 2007.

[5] R. Vengrenovich, B. Ivanskii, and A. Moskalyuk, Mass Transfer-Advanced Aspects, In Tech, Rijeka, Croatia, 2011.

[6] Z. F. Wu, M. Q. Zeng, L. Z. Ouyang, X. P. Zhang, and M. Zhu, "Ostwald ripening of $\mathrm{Pb}$ nanocrystalline phase in mechanically milled $\mathrm{Al}-\mathrm{Pb}$ alloys and the influence of $\mathrm{Cu}$ additive," Scripta Materialia, vol. 53, no. 5, pp. 529-533, 2005.

[7] P. E. J. R. D. del Castillo, P. Reischig, and S. van der Zwaag, "Tailoring of Ostwald ripening behaviour in multicomponent Al alloys," Scripta Materialia, vol. 52, no. 8, pp. 705-708, 2005.

[8] D.-K. Lee and N.-M. Hwang, "Thermodynamics and kinetics of monodisperse alloy nanoparticles synthesized through digestive ripening," Scripta Materialia, vol. 61, no. 3, pp. 304-307, 2009.

[9] U. Hartmann, Faszination Nanotechnologie, Elsevier, Spektrum Akademischer, Heidelberg, Germany, 2006.

[10] S. A. Kukushkin, A. V. Osipov, F. Schmitt, and P. Hess, "The nucleation of coherent semiconductor islands during the Stranski-Krastanov growth induced by elastic strains," Semiconductors, vol. 36, no. 10, pp. 1097-1105, 2002.

[11] N. A. Cherkashin, M. V. Maksimov, A. G. Makarov et al., "Control over the parameters of InAs-GaAs quantum dot arrays in the Stranski-Krastanow growth mode," Semiconductors, vol. 37, no. 7, pp. 861-865, 2003.

[12] V. N. Nevedomskii, N. A. Bert, V. V. Chaldyshev, V. V. Preobrazhenskii, M. A. Putyato, and B. R. Semyagin, "GaAs structures with InAs and As quantum dots produced in a single molecular beam epitaxy process," Semiconductors, vol. 43, no. 12, pp. 1617-1621, 2009.

[13] M. Bürger, T. Schupp, K. Lischka, and D. As, "Cathodoluminescence spectroscopy of zinc-blende GaN quantum dots," Physica Status Solidi C, vol. 9, no. 5, pp. 1273-1277, 2012.

[14] P.-S. Kuo, B.-C. Hsu, P.-W. Chen, P. S. Chen, and C. W. Liu, "Recessed oxynitride dots on self-assembled Ge quantum dots grown by LPD," Electrochemical and Solid-State Letters, vol. 7, no. 10, pp. G201-G203, 2004.

[15] R. D. Vengrenovich, Y. V. Gudyma, and S. V. Yarema, "Dislocation mechanism of quantum dot formation in heteroepitaxial structures," Physica Status Solidi B, vol. 242, no. 4, pp. 881-889, 2005.

[16] R. D. Vengrenovich, B. V. Ivanskii, and A. V. Moskalyuk, "Ostwald ripening of nanoislands in semiconductor heterosystems and its influence on optical properties," Opto-Electronics Review, vol. 18, no. 2, pp. 168-175, 2010.

[17] I. N. Stranski and L. Krastanov, "Theory of orientation separation of ionic crystal," Sitzungsberichte Der Akademie Der Wifienschaften. Wien. Mathematisch-Naturwifienschaftlich Klasse, Abteilung IIB, vol. 146, pp. 797-810, 1937.

[18] A. de Kergommeaux, J. Faure-Vincent, A. Pron, R. de Bettignies, B. Malaman, and P. Reiss, "Surface Oxidation of Tin Chalcogenide Nanocrystals Revealed by ${ }^{119} \mathrm{Sn}$-Mössbauer Spectroscopy," Journal of the American Chemical Society, vol. 134, no. 28, pp. 11659-11666, 2012.

[19] A. Layek, G. Mishra, A. Sharma et al., "A generalized three-stage mechanism of $\mathrm{ZnO}$ nanoparticle formation in homogeneous liquid medium," The Journal of Physical Chemistry C, vol. 116, pp. 24757-24769, 2012. 
[20] R. Viswanatha, H. Amenitsch, and D. D. Sarma, "Growth kinetics of $\mathrm{ZnO}$ nanocrystals: a few surprises," Journal of the American Chemical Society, vol. 129, no. 14, pp. 4470-4475, 2007.

[21] R. Viswanatha, P. K. Santra, C. Dasgupta, and D. D. Sarma, "Growth mechanism of nanocrystals in solution: $\mathrm{ZnO}$, a case study," Physical Review Letters, vol. 98, Article ID 255501, 4 pages, 2007.

[22] L. Mädler, W. J. Stark, and S. E. Pratsinis, "Rapid synthesis of stable $\mathrm{ZnO}$ quantum dots," Journal of Applied Physics, vol. 92, no. 11, pp. 6537-6540, 2002.

[23] S. Tutashkonko, T. Nychyporuk, V. Lysenko, and M. Lemiti, "Thermally induced Ostwald ripening of mesoporous Ge nanostructures," Journal of Applied Physics, vol. 113, Article ID 023517, 8 pages, 2013.

[24] A. P. Thurber, G. Alanko, L. Beausoleil II, K. N. Dodge, C. B. Hanna, and A. Punnoose, "Unusual crystallite growth and modification of ferromagnetism due to aging in pure and doped ZnO nanoparticles,", Journal of Applied Physics, vol. 111, Article ID 07C319, 3 pages, 2012.

[25] S. Mahamuni, K. Borgohain, B. S. Bendre, V. J. Leppert, and S. H. Risbud, "Spectroscopic and structural characterization of electrochemically grown $\mathrm{ZnO}$ quantum dots," Journal of Applied Physics, vol. 85, no. 5, pp. 2861-2865, 1999.

[26] H. Kreye, "Einflus von Versetzungen auf die Umlosung von Teilchen," Zeitschrift Für Metallkunde, vol. 61, pp. 108-113, 1970.

[27] R. D. Vengrenovich, "Onkinetics of coalescence of disperse extractions at dislocation network," FMM, vol. 39, pp. 435-439, 1975.

[28] R. D. Vengrenovich, Y. V. Gudyma, and S. V. Yarema, "Ostwald ripening under dislocation diffusion," Scripta Materialia, vol. 46, no. 5, pp. 363-367, 2002.

[29] R. D. Vengrenovich, A. V. Moskalyuk, and S. V. Yarema, "Island size distribution under conditions of dislocation-surface diffusion in semiconductor heterostructures," Semiconductors, vol. 40, no. 3, pp. 270-275, 2006.

[30] R. D. Vengrenovich, A. V. Moskalyuk, and B. V. Ivanskii, "Ostwald's ripening of quantum-dimensional nanocrystals in conditions of the mixed diffusion," Metallofizika i Noveishie Tekhnologii, vol. 30, no. 2, pp. 247-266, 2008.

[31] R. D. Vengrenovich, "On the Ostwald ripening theory. Overview 20," Acta Metallurgica, vol. 20, pp. 1079-1086, 1982.

[32] G. M. Novotny and A. J. Ardell, "Precipitation of Al3Sc in binary Al-Sc alloys," Materials Science and Engineering A, vol. 318, no. 1-2, pp. 144-154, 2001.

[33] C. B. Fuller and D. N. Seidman, "Temporal evolution of the nanostructure of $\mathrm{Al}(\mathrm{Sc}, \mathrm{Zr})$ alloys: part II-coarsening of $\mathrm{Al} 3\left(\mathrm{Sc}_{1-x} \mathrm{Zr}_{x}\right)$ precipitates," Acta Materialia, vol. 53, no. 20, pp. 5415-5428, 2005. 

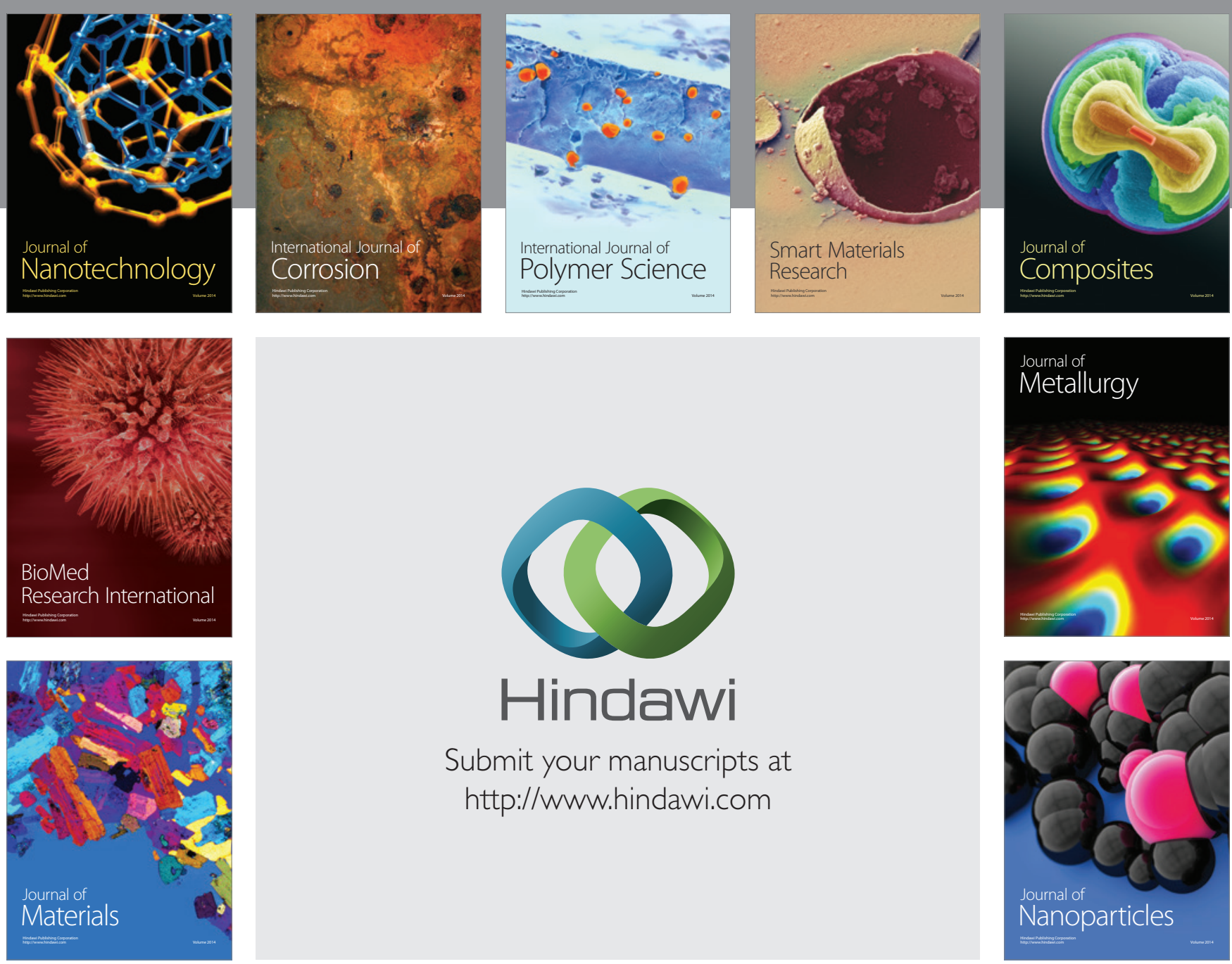

Submit your manuscripts at http://www.hindawi.com
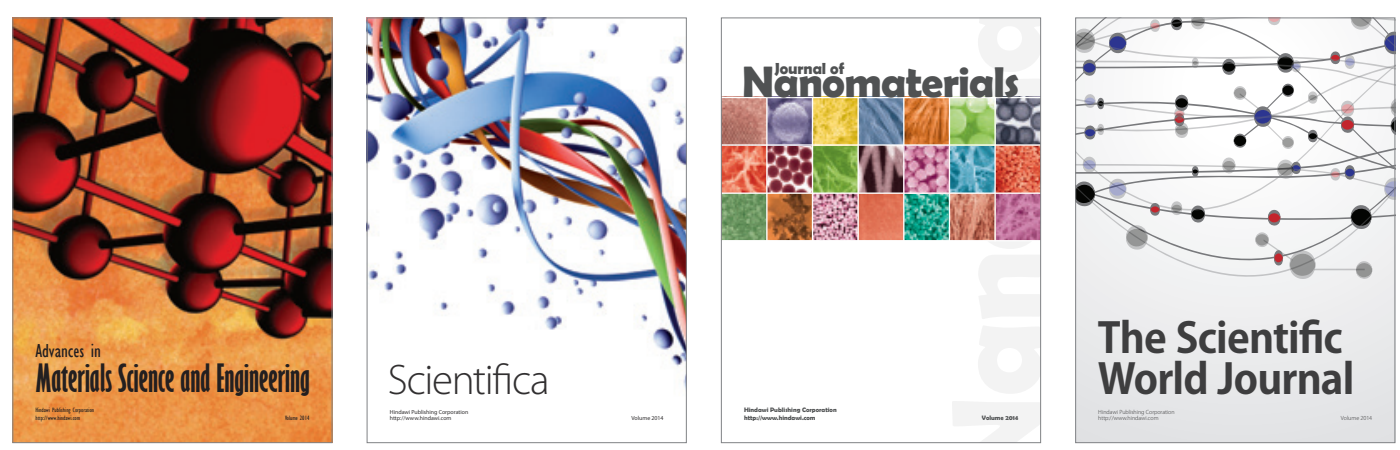

\section{The Scientific World Journal}
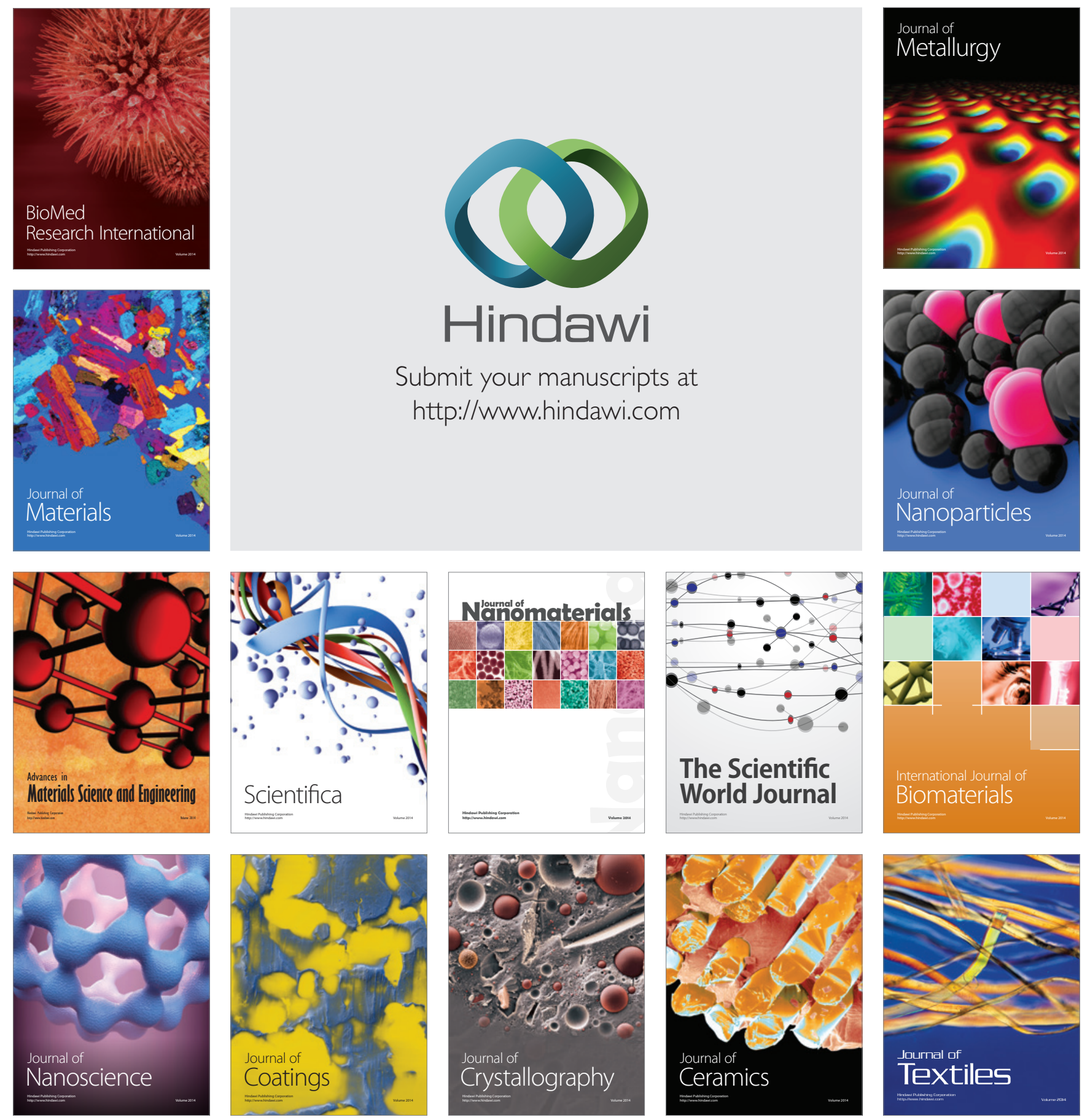